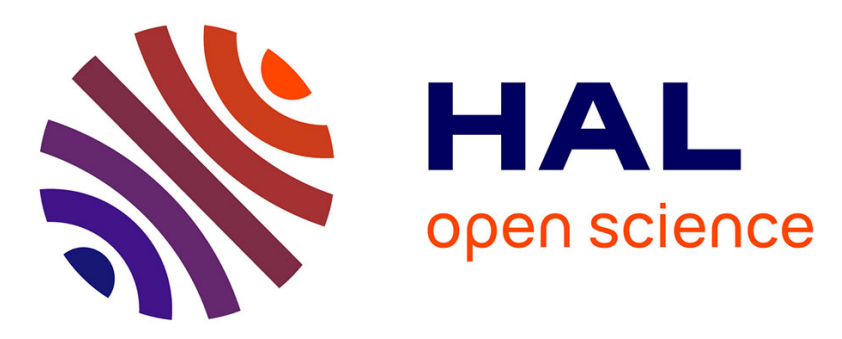

\title{
Fuel reforming for scramjet thermal management and combustion optimization
}

E.A Daniau, Marc Bouchez, Olivier Herbinet, Paul-Marie Marquaire, Nicolas Gascoin, Philippe Gillard

\section{- To cite this version:}

E.A Daniau, Marc Bouchez, Olivier Herbinet, Paul-Marie Marquaire, Nicolas Gascoin, et al.. Fuel reforming for scramjet thermal management and combustion optimization. A Collection of Technical Papers - 13th AIAA/CIRA International Space Planes and Hypersonic Systems and Technologies Conference, 2005, 3, pp.1799-1807. 10.2514/6.2005-3403 . hal-00641636

\section{HAL Id: hal-00641636 https://hal.science/hal-00641636}

Submitted on 16 Nov 2011

HAL is a multi-disciplinary open access archive for the deposit and dissemination of scientific research documents, whether they are published or not. The documents may come from teaching and research institutions in France or abroad, or from public or private research centers.
L'archive ouverte pluridisciplinaire HAL, est destinée au dépôt et à la diffusion de documents scientifiques de niveau recherche, publiés ou non, émanant des établissements d'enseignement et de recherche français ou étrangers, des laboratoires publics ou privés. 


\title{
Fuel reforming for scramjet thermal management and combustion optimization
}

\author{
E. DANIAU* ${ }^{*}$, M. BOUCHEZ ${ }^{\dagger}$ \\ MBDA-France, 8 rue Le Brix, 18020 Bourges Cedex, France \\ O. HERBINET ${ }^{\ddagger}$, P.M. MARQUAIRE ${ }^{\S}$ \\ DCPR, UMR 7630 CNRS-INPL, 1 rue Grandville, 54000 Nancy, France \\ and \\ N. GASCOIN ${ }^{* *}$, P. GILLARD ${ }^{\dagger \dagger}$ \\ Laboratoire Energétique, Explosion, Structure - 63, nue de Lattre de Tassigny - 18020 Bourges Cedex
}

\begin{abstract}
It is common knowledge that one of the main issues of hypersonic flight is the thermal management of the overall vehicle and more specifically the cooling of the engine, since even composite materials can't withstand the large heat load found in a Scramjet combustion chamber. Another critical point is that mixing and combustion should be sufficiently fast in order to avoid long combustion chamber caused by supersonic internal flow and short residence time. Cryogenic fuels are a logical choice but their lack of storability and low density make them second choice compared to liquid hydrocarbons for small vehicle application. Researches are currently conducted in order to determine if the cooling can be achieved by the endothermic thermal decomposition of the fuel itself circulating trough the engine. The other benefit of this decomposition is the expected shift in the fuel mole fraction, from heavy hydrocarbons (with long induction delays), to light species (mainly $\mathrm{H}_{2}, \mathrm{CH}_{4}$ and $\mathrm{C}_{2} \mathrm{H}_{4}$ ). In order to quantify the heat transfer in the cooled structures and the composition of the cracked fuel entering the combustor, an accurate predictive model of the thermal decomposition of the fuel is required. For this purpose, an experimental and modeling study of the thermal decomposition of generic molecules (typically long-chain alkanes and polycyclic non-aromatic complex molecules) that could be good surrogates of real fuels, has been started at the DCPR laboratory. The thermal decomposition of those generic molecules is studied in an isothermal jet-stirred reactor. Products of the thermal decomposition are heavy species like aromatics and poly-aromatics and lighter species like hydrogen, methane, ethylene and other middle-weight alkenes. Those results allowed the validation of the kinetic models that have already been developed. During the same time, MBDA-F launched collaborative project named COMPARER, focusing on system analysis to identify one or two characteristic parameters (able to be measured) needed to understand and control the complex phenomena involved in the presented cooling technology and to evaluate some associated sensors. Laminar flame speed for different fuel composition were computed in order to be able to tune the mixture for the lowest possible ignition delay. If at first glance a high mole fraction of hydrogen seems to be interesting, this generally also lead to a high mole fraction of methane (a molecule well known for its long ignition delay and an un-welcomed product) and high mole fractions of middle-weight species (such as ethylene, acetylene, butadiene, cyclopentadiene...) seems to be more promising from a combustion point of view.
\end{abstract}

\footnotetext{
*Aerospace engineer, emeric.daniau@mbda.fr, AIAA Member.

${ }^{\dagger}$ Aerospace engineer and senior propulsion expert, marc.bouchez@mbda.fr, AIAA Member.

${ }^{\ddagger}$ PhD, olivier.herbinet@ensic.inpl-nancy.fr.

§CNRS, paul-marie.marquaire@ensic.inpl-nancy.fr.

**PhD, Nicolas.Gascoin@bourges.univ-orleans.fr.

${ }^{{ }^{\dagger}}$ University professor, Philippe.Gillard@bourges.univ-orleans.fr.
} 


\section{Nomenclature}

C/SiC : carbon / silicon carbide composite

CC : Combustion Chamber

DMR : Dual Mode Ramjet

PAH : Polycyclic Aromatics Hydrocarbons

$\lambda:$ thermal conductivity $\left(\mathrm{W} \cdot \mathrm{m}^{-1} \cdot \mathrm{K}^{-1}\right)$

$\rho$ : density $\left(\mathrm{kg} \cdot \mathrm{m}^{-3}\right)$

$C_{P}$ : heat capacity $\left(\mathrm{J} \mathrm{kg}^{-1} \cdot \mathrm{K}^{-1}\right)$

$\eta$ : viscosity (Pa.s)

\section{Introduction}

Hypersonic flight is expected to be achieved with dual-mode-Ramjet (Ramjet under Mach 6 and Scramjet beyond) because of its high specific impulse and its capability to be reusable (especially interesting for space transportation $)^{1}$, but one of the main issues at these flight conditions is the thermal management of the engine and the vehicle. Different cooling strategies have been evaluated by MBDA-France (calculations, material tests). Metallic panels have been tested as composite ones $(\mathrm{C} / \mathrm{SiC})^{2}$, which seem to be promising. But even composite materials could not withstand such large heat load (for example, total temperature of external air reaches $4950 \mathrm{~K}$ at Mach 12). Consequently an active cooling system has to be used but not a dedicated one because it would increase the vehicle weight. Furthermore, another issue occurs under theses flight conditions. The time allocated to mix the injected fuel with inlet air, to ignite the combustion and to complete it before the chamber outlet is about 1 ms.

These two points lead to the so-called "regenerative cooling" solution : using the fuel to cool down the engine's wall and then burning it in the CC. The fuel is injected in a composite channel (which surrounds the engine) near the outlet of the CC, it flows to the injection on the opposite way of the burned gases. A heavy hydrocarbon fuel is chosen here because of its high density compared to cryogenic fuels $\left(800 \mathrm{~kg} \cdot \mathrm{m}^{-3}\right.$ instead of $70 / 80 \mathrm{~kg} \cdot \mathrm{m}^{-3}$ for cryogenic hydrogen, with a specific impulse of liquid hydrocarbon halved) ${ }^{3}$. When heated and pyrolysed, it produces lighter hydrocarbons species that are both more energetic and easier to ignite. This point allows responding to rapid phenomenon in the $\mathrm{CC}$.

But this cooling system requires knowing firstly how the fuel is decomposed and ensures the cooling and secondly how it will burn in the CC (to manage the thrust). It has to be noticed that due to the expected high pressure in the cooling loop (>3 MPa) the fluid becomes supercritical in the channel, which leads to some modelling difficulties (fluid properties and flow rate measurement) for the cooling study. The injected flow rate is expected to be slightly different from the one pumped out of the tank because a carbon deposit (coke) could appears at high temperature (above $1000 \mathrm{~K}$ ) and because transpiration cooling is planned to be used through the mastered porosity of the $\mathrm{C} / \mathrm{SiC}$ wall. This phenomenon will also change the carbon/hydrogen ratio of the fuel in the channel. This point needs to be studied because it influences the combustion and $a$ priori the thrust. 


\section{Overview of MBDA-France activities}

In addition to the long established cooperation with ONERA ${ }^{4}$ on this topic, MBDA launched two small-scale programs in collaboration with French laboratories and universities.

\section{A. The COMPARER project}

COMPARER is the French acronym for " COntrol and Measure of PArameters in a REacting stReam". The aim of this project is to identify one or two characteristic parameters (able to be measured) needed to understand and control the complex phenomena involved in the presented cooling technology and to evaluate some associated sensors.

The different actors of this program are MBDA-F, the "Laboratoire Energétique, Explosions et Structures" (LEES, explosions dynamics and reactive systems laboratory), the "Laboratoire de Vision et de Robotique" (LVR, vision and robotics laboratory) and the "Pôle Capteur" (excellence centre for sensors), all located near Bourges, in France.

The used strategy is to first determine the different parts of the engine involved in the cooling. Then, steady simulations have been conducted with a specific $\operatorname{code}^{6}$ developed thanks to the existing in-house MBDA program (called NANCY). We use a pyrolysis mechanism ${ }^{7}$ for the n-dodecane written in CHEMKIN II format. The code allows taking into account the endothermic effects on the wall cooling ${ }^{8}$.

In order to identify the possible and interesting control measurements, some generic engines were studied in steady conditions, and the different parts of the coupling cooling/bruning loop was analyzed with pluridisciplinary, simplified but unsteady approach.

This sensitivity analysis allowed us to pinpoint critical parameters and to develop strategies to implement the measurement of those parameters in a real engine.

The next step of this program is to build a research test bench (Figure 1) that will enable the development and calibration of specific sensors that could be used for the on-board regulation of a DMR.

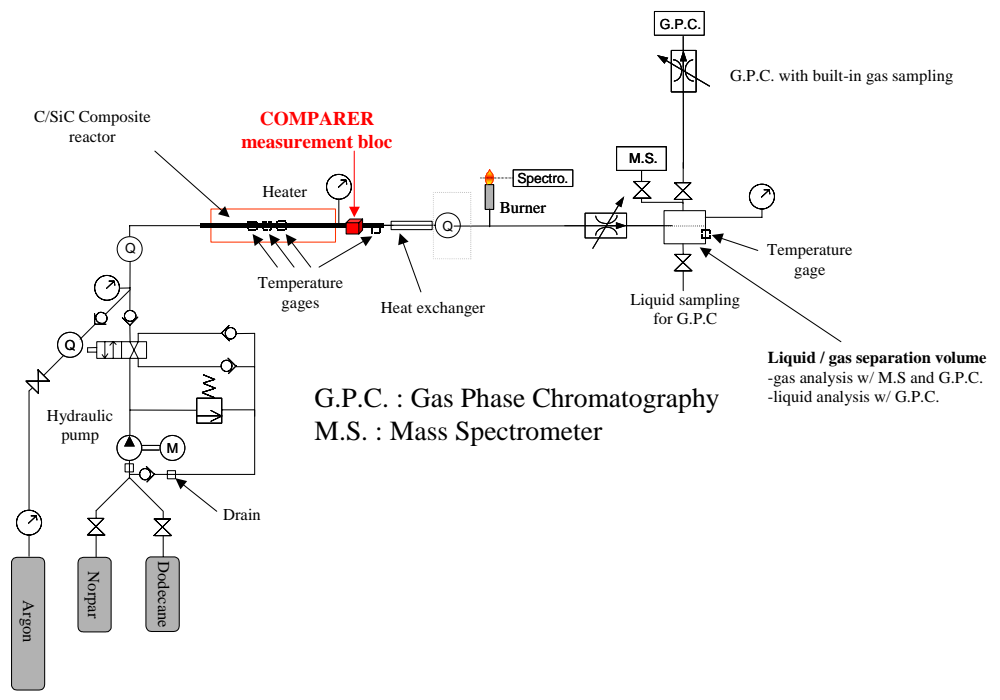

Figure 1. COMPARER test bench.

The fuel is flowing through a metallic or $\mathrm{C} / \mathrm{SiC}$ reactor installed in a high temperature oven $(1800 \mathrm{~K})$ and then passes through a measurement prototype block, then is cooled and burnt in an academic flame.

This working bench will be used to validate the unsteady model of the engine and to evaluate different real time measurement techniques on the decomposed fuel : mass flow, decomposition level and capacity to burn.

The identified techniques can be tested on laboratory level on the fuel, at the exit of the reactor (located as "COMPARER measurement bloc" in Figure 1), with steady or unsteady conditions (temperature, fuel mass flow rate, etc). At least for steady operating points, some characterization is planned both on the decomposition of the fuel and on the academic burner, in order to analyze the COMPARER real time measurements.

Due to security and sizing consideration, the fuel mass flow rate in this reactor will be very low $\left(0.1 \mathrm{~g} . \mathrm{s}^{-1}\right)$ This way, the burner power is limited to $5 \mathrm{~kW}$ and a real time spectroscopy could be used as the main diagnostic device.

The main diagnostic method on this test bench will be the Gas Phase Chromatography coupled to a Mass Spectrometer. Those two methods will be used to cross-checked the results obtained with the COMPARER sensor. 


\section{B. MBDA-F - DCPR collaboration}

The DCPR is a worldwide-known laboratory heavily involved in the study of fuel oxidation and thermal decomposition and located in Nancy, France. In collaboration with MBDA-F, some kinetic models were developed and validated against experimental data obtained in a perfectly stirred quartz reactor (Figure 2).

The maximum possible temperature in a quartz reactor is near $1300 \mathrm{~K}$. The fuel models include a full scheme primary mechanism, a lumped secondary mechanism and a Polycyclic Aromatic Hydrocarbons $(\mathrm{PAH})$ and soot formation mechanism. A typical mechanism involve more than 1500 elementary reactions and 300 compounds.

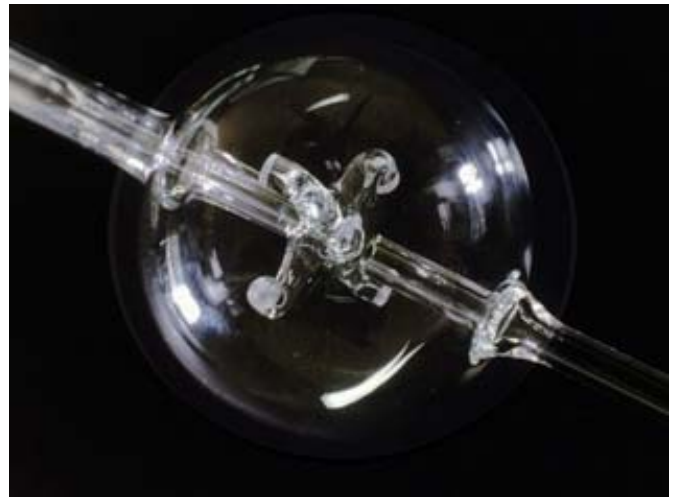

Figure 2. A perfectly stirred quartz reactor.

\section{Fuel kinetics models}

\section{A. Cooled engine modeling}

To compute the active cooling of such an engine, the semi-empirical NANCY code is extensively used by MBDA FRANCE. This code deals with stationary heat exchanges between two fluids flowing upstream. Implemented fluids are air, water and hydrogen, but it is possible to input other fluids (such as kerosene or endothermic hydrocarbons ${ }^{9}$ ) by defining their thermal characteristics versus their temperature and pressure. The code calculates step by step walls and fuel temperatures of each section and thus the cooling of the panels. Moreover it estimates thermal and mechanical stresses in the coolant channel material and computes the pressure drop.

Further investigation is currently taking benefit of more complex modelling such as 3D thermalhydraulic computations ${ }^{10}$ or hydrocarbon fuel kinetic modelling, under current development for industrial use by MBDA FRANCE with some research institutes.

Another interest is the capability to check the unsteady behaviour of such a cooled structure.

For the PTAH technology, several system "paper" studies have been performed, mainly on dual-mode ramjets (with hydrogen or hydrocarbon as fuel). Preliminary investigation has also been performed on Liquid-Rocket Engines.

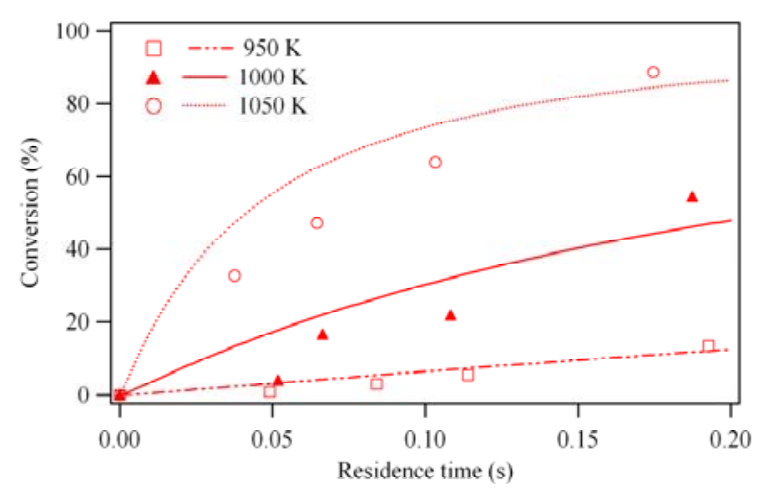

Figure 3. Conversion of type 1 molecule as a function of temperature and residence time.

\section{B. Fuel selection and modeling}

Two molecules were selected for the development of a kinetic fuel model. One is a long-chain alkane (type 1) and the other is a non-aromatic, poly-cyclic compound (type 2). Those two very different molecules were selected in order to obtain a better understanding of the thermal behavior of linear and cyclic hydrocarbons.

The primary model is sufficient to describe the decomposition of the initial molecule, but the secondary model is needed to gain the knowledge of the products distribution.

The Figure 3 shows some validation cases of the primary model of the type 1 molecule. This model is relatively simple and contains 500 reactions and 100 compounds. 
The Figure 4 shows the conversion profile of the type 2 molecule (cyclic) as a function of the temperature and for a residence time inside the reactor of 1 second.

The dots represent the experimental points and the line is the result of the kinetic primary model. This model is more complex than the previous one, with 1700 reactions and 350 compounds.

Both models shows the utmost importance of the temperature in the decomposition of an endothermic fuel.

In the case of a long-chain alkane, the conversion at $950 \mathrm{~K}$ for a very short residence time of $0.05 \mathrm{~s}$ is very low (less than $5 \%$ ). If we double the residence time $(0.1 \mathrm{~s})$, the conversion increases to a modest $5 \%$ and if we double again the residence time (0.2 s), the conversion reaches only $12 \%$.

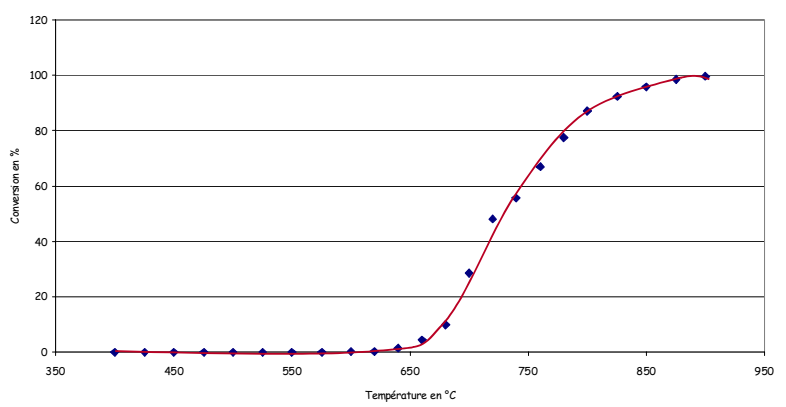

Figure 4. Conversion of type 2 molecule as a function of the temperature for a $1 \mathrm{~s}$ residence time.

In contrast, a modest increase of the temperature by $50 \mathrm{~K}$ (from $950 \mathrm{~K}$ to $1000 \mathrm{~K}$, a small $5 \%$ increase) leads to $17 \%$ conversion (instead of less than $5 \%$ ). A further increase by $50 \mathrm{~K}$ (at $1050 \mathrm{~K}$ ) increases the conversion rate between $40 \%$ and $55 \%$.

\section{Fluid composition in a cooling channel}

Different test cases have been calculated for various heat wall fluxes, channel length and configuration, fuel flow rate, pressure condition.

The Figure 5 shows the fuel remaining mole fraction as a function of the fuel temperature.

We could conclude that for a limited range of residence time (from tenth of seconds to seconds), the pyrolysis of long-chain alkane is principally temperature dependent except in a small area where the conversion rate is maximal (slightly above $1000 \mathrm{~K}$ ).

Previous computations taking into account the fuel mass flow rate and the expected heat fluxes show that the fuel temperature in our DMR engine is expected to reach $1300 \mathrm{~K}$ and maybe up to $1500 \mathrm{~K}$ in some cases, such high temperatures leading to a clear $100 \%$

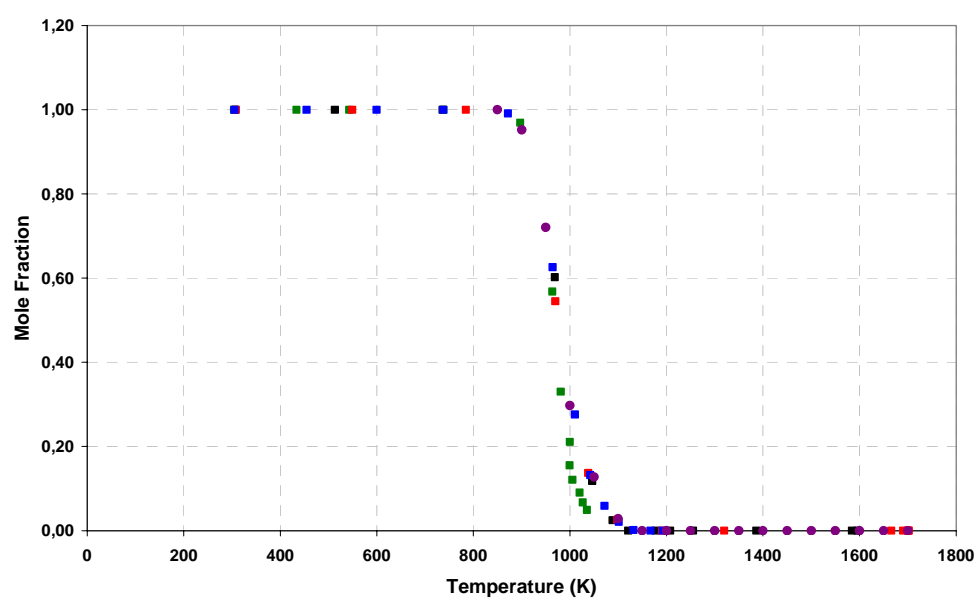

Figure 5. Main effect of the temperature on the chained alkane pyrolysis (different elementary reactors with various residence times from $0,1 \mathrm{~s}$ to $1 \mathrm{~s})$

conversion degree.

With the decomposition of the initial molecule, a lot of secondary products could be found in the fuel (Figure 6). For the chained alkane, the main products are ethylene $\left(\mathrm{C}_{2} \mathrm{H}_{4}\right)$, ethane $\left(\mathrm{C}_{2} \mathrm{H}_{6}\right)$ methane $\left(\mathrm{CH}_{4}\right)$ and hydrogen at high temperature $\left(\mathrm{H}_{2}\right)$ ).

The case of hydrogen is very interesting because it's production rate in the primary mechanism is very low and that any large mole fraction of $\mathrm{H}_{2}$ imply also a large number of lowly hydrogenated components such as benzene $\left(\mathrm{C}_{6} \mathrm{H}_{6}\right)$, toluene $\left(\mathrm{C}_{7} \mathrm{H}_{8}\right), \mathrm{PAH}$ and even coke. 
From Figure 6, it appears that the pyrolysis of long chain alkanes occurs in two step. The first step involve the decomposition of the initial molecule and the formation of a wide range of middle-weight compounds, mainly alkenes and alkanes.

After this step, and if the temperature increases again, the middle-weight compounds start their pyrolysis with the formation of hydrogen, methane and coke

For the type 2 (polycyclic) molecule, the products distribution exhibits some notable differences (Figure 7).

In this case, hydrogen is a major product, followed by ethylene and methane (even at "low" temperature). This high hydrogen production is directly linked to the production of benzene and other aromatics like toluene, styrene, indene and naphtalene.

Due to the ring shape of this molecule, a relatively large amount of cyclopentadiene is also produced.

It should be noticed that benzene is produced directly in the primary mechanism, another difference between type 1 and type 2 molecules.

The amount of PAH produced by the cyclic molecule is higher than that produced by the chained alkane, but the PAH formation is not linked to the primary mechanism and is not a direct function of the fuel conversion rate.

Figure 8 shows the remaining mass fraction of the cyclic compound as a function of the residence time and the temperature. The PAH mass fraction is also represented.

For a fuel temperature of $933 \mathrm{~K}$, the conversion of initial fuel is less than $30 \%$, even after 5 seconds. In this case, the PAH mass fraction is $2 \%$. The same degree of fuel conversion could be achieved if the fuel temperature is raised to $973 \mathrm{~K}$ with a residence time of less than 1 second, but the PAH mass fraction is only $1 \%$.

So if we want to maximise the fuel conversion and minimise the $\mathrm{PAH}$ formation, one should select a high fuel temperature with a low residence time (and a short cooling loop with high fuel speed).

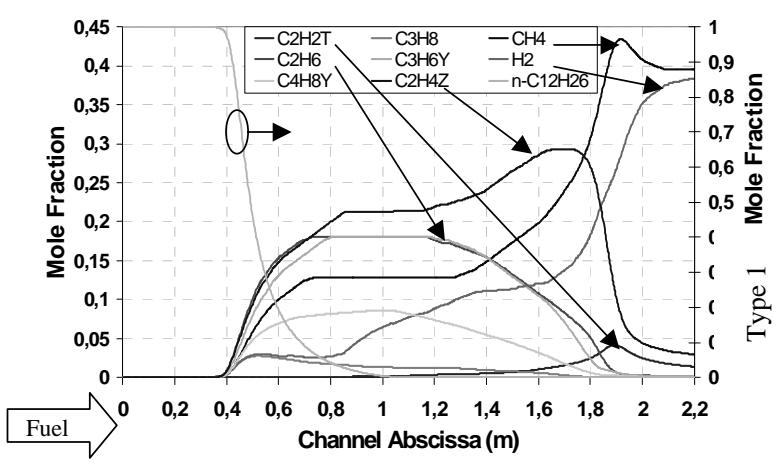

Figure 6. Repartition of components concentrations in a cooling channel of a generic DMR (long chain alkane).

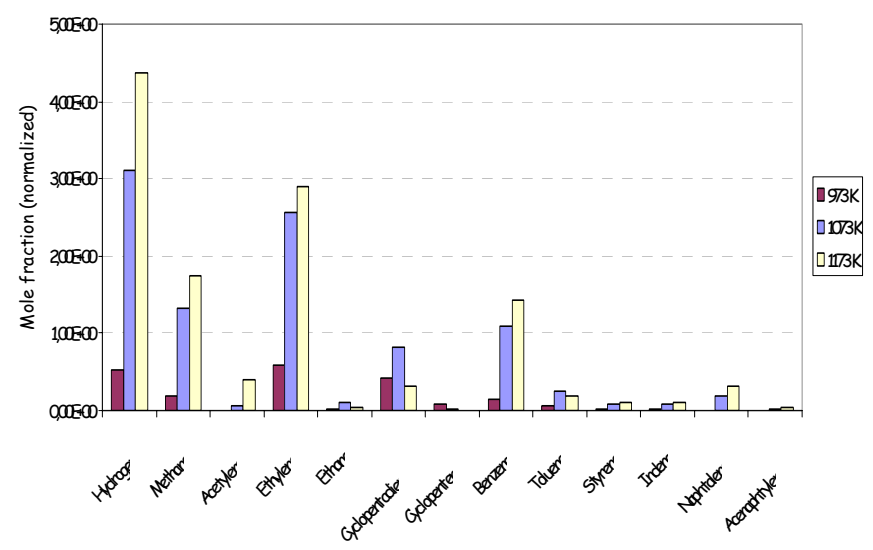

Figure 7. Main decomposition product distribution of a polycyclic non-aromatic molecule (type 2 ) as a function of the reactor temperature (residence time, $1 \mathrm{~s}$ ).

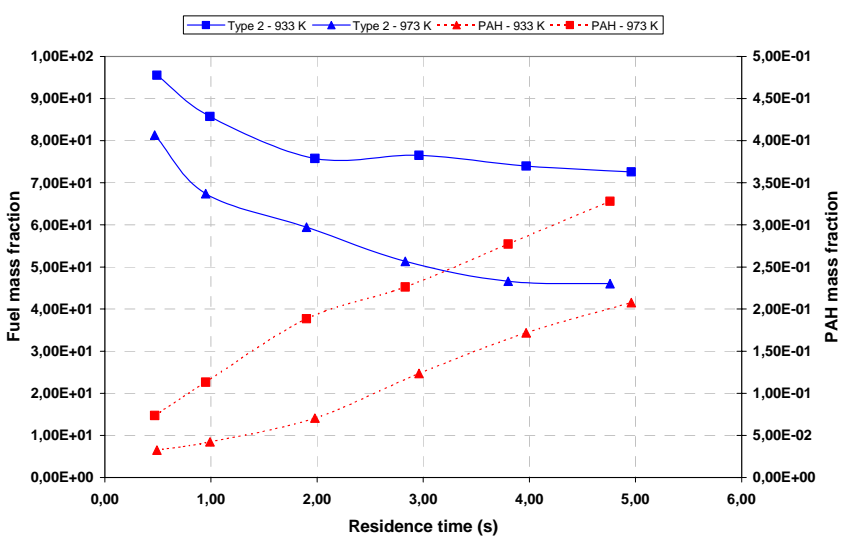

Figure 8. Type 2 molecule remaining mass fraction and PAH formation as a function of fuel temperature and residence time. 


\section{Fuel combustion}

\section{A. Predicting the fuel burning capability}

Giving the fact that temperature is the first parameter governing the decomposition of hydrocarbons fuel, this parameter could be sufficient to know the pyrolysed mixture composition before injection in the combustion chamber. But to control the scramjet in terms of thrust, it is needed to predict how the injected fuel can burn. A criterion has to be found to represent the capacity for the mixture to burn. The inflammation delay could be chosen although other criteria like the fundamental flame velocity or the activation energy are of great interest. It can be chosen that the ignition delay should not be greater than $0.1 \mathrm{~ms}$. It corresponds roughly to a tenth of the combustion chamber length as it is confirmed in the literature ${ }^{11}$. As we do not have a full combustion mechanism involving all and every species for our main fuel and all its pyrolysis products, we are not able to calculate such delay with PREMIX $^{12}$ and SENKIN ${ }^{13}$ but we could at least calculate the delay of a large number of alkanes and alkenes.

Because production of species is not a linear phenomenon, it is possible to expect an "ideal" composition of mixtures for a burning application.

As an example, Figure 6 shows the different species mole fraction in a cooling channel. As some species are more able to burn than others, it is interesting to determine an "ideal" composition which could respond to the chosen criterion of $0.1 \mathrm{~ms}$. Davidenko et al. ${ }^{14}$ estimates that a $20 \%$ in mass of hydrogen is needed in a binary mixture of methane and hydrogen for the combustion in scramjet. It should be reminded that hydrogen - air mixtures typically exhibit the smallest ignition delay of all gaseous hydrocarbons and that methane - air mixtures, on the other hand, exhibit the longest ignition delay.

Due to the lack of data, we need to find a way to determine whether a mixture agree with this criterion. We adopt these of , considering that all "good" species in terms of combustion are as good as hydrogen. Then, this choice allows us to compute inflammation delays with PREMIX or SENKIN for any compound found in our fuel mixture, as for example hydrogen, methane, ethane and so on.

The Figure 9 shows some laminar flame speed for different fuel composition. On the left side of the diagram we found the results obtained for two reference DMR and the associated experimentations (with two different specific conditions), on the right the comparison between the computed laminar flame speed of pure compounds and some references, and between the two a generic mixture of methane and hydrogen.

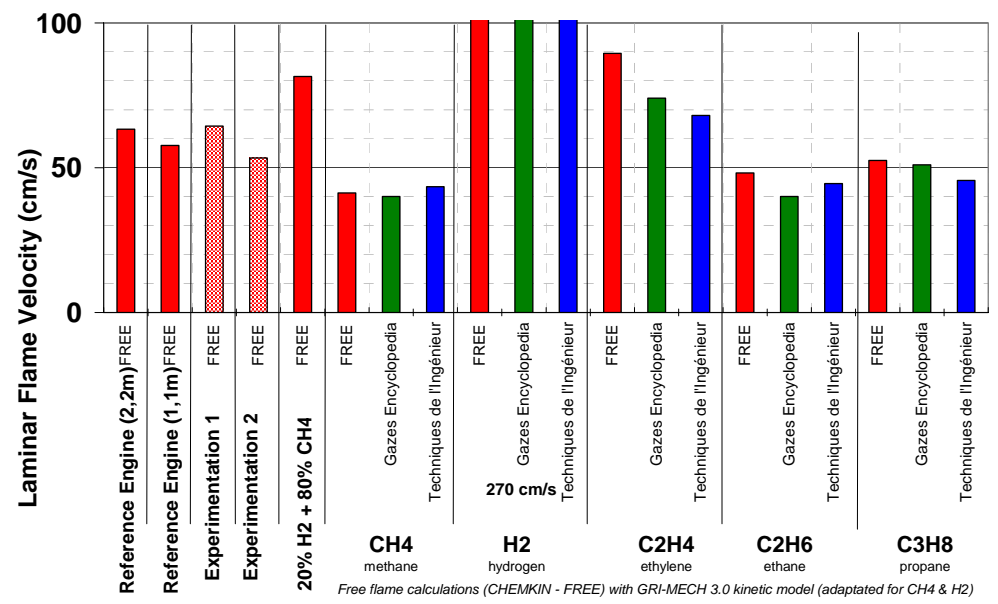

Figure 9. Laminar flame speed for different pure hydrocarbons and mixtures.

It is too early to surely associate a criterion to control an actual regeneratively-cooled hydrocarbon-fueled DMR, but this analyses allows to identify some relationship between the composition or the characteristics (physical, optical, chemical, electrical, ...) of the decomposed fuel and its general capability to burn easily.

We decided to use combustion mechanism found in the literature (like those of San Diego, GRI-Mech) and specially made for certain species. Thanks to these ignition delays for different species or mixtures (function of initial fluid temperature), we have classified compounds in "good" or "bad" in terms of ignition. Products with higher inflammation delay than methane and hydrogen (20\% in mass) are considered as bad species. This classification permits to determine whether a mixture contains enough good species to respond to the $0.1 \mathrm{~ms}$ criterion or not.

If we look at the Figure 6 again, we see that near the $1 \mathrm{~m}$ abscissa the fuel is mainly composed of ethylene, ethane, methane, propene and hydrogen. 
Ethylene have a lower laminar flame speed $\left(0.73 \mathrm{~m} . \mathrm{s}^{-1}\right)$ than hydrogen $\left(2.65 \mathrm{~m} . \mathrm{s}^{-1}\right)$ or acetylene $\left(1.46 \mathrm{~m} . \mathrm{s}^{-1}\right)$ but is still one $\mathrm{f}$ the easiest burning hydrocarbons. Its molar weight of $28 \mathrm{~g}$ is also higher than that of methane (16 g) or hydrogen ( $2 \mathrm{~g})$, so a high mole fraction of ethylene leads also to a high weight fraction.

On the same figure, we could see that when the temperature increase the fuel products distribution narrowed and if the temperature increase too much, the main products are only methane and hydrogen. In that case, it is also clear that a lot of coke should be produced and that most of the fuel mass flow stays in the cooling loop (forming gums and tar).

So it is clear than even if there is more hydrogen in the mixture at the abscissa of $2.2 \mathrm{~m}$ than at the abscissa of $1 \mathrm{~m}$, the mixture will be less efficient in term of burning capability, which is another key parameter (with the cooling capacity, of course) when studying regenerative cooling.

\section{B. Measuring fuel burning capability}

In order to be able to control the engine and the fuel ability to burn quickly (composition), some fuel diagnostic are needed onboard the engine.

After a review of the possible measurement methods, passive IR spectroscopy was selected as one of the promising and usable ways.

Some computations of the fuel IR spectrum, as a function of the fuel temperature and composition, have been done with the HITRAN software ${ }^{15}$. This work enable us to identify some interesting wavelengths. For example, one is located at $4170 \mathrm{~cm}^{-1}$ and its intensity is directly related to the methane mole fraction inside the mixture (Figure 10).

The COMPARER test bench will prove to be a useful tool for testing the application of narrow-band, real-time IR spectroscopy to fuel analysis for engine control.

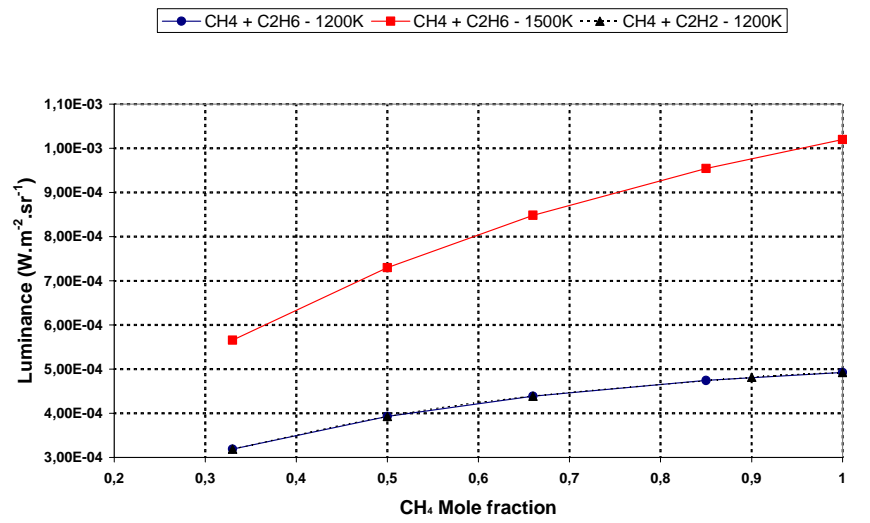

Figure 10. intensity of the $4170 \mathrm{~cm}^{-1}$ wavelength as a function of the temperature and the $\mathrm{CH}_{4}$ mole fraction.

\section{Conclusion}

In order to gain some additional knowledge on fuel thermal decomposition for regenerative cooling DMR application, MBDA-France funded two small-scale studies.

With the collaboration of the French DCPR laboratory, a complete model for the pyrolysis of long-chain alkane was developed and validated in a broad range of pressure and temperature. No supercritical phase fluid effect was explicitly taken into account and some discrepancy in pyrolysis products composition was found between computations and literature experimental results, but the general agreement between numerical and experimental results is quite good. This kinetic model was then integrated in a in-house semi-empirical thermal model (NANCY, used by MBDA-France) and a specific package was developed in order to calculate the cooling fluid physical properties as a function of the fluid chemical composition.

This integrated software should be very useful for the comprehension of the mechanism and the design of a regenerative cooled scramjet combustion chamber which are currently under investigation by MBDA.

The success of this approach lead to the study of a second kind of molecule that could be found in a real aviation fuel. The primary kinetic model was developed and experimentally validated. A secondary model, including PAH and coke formation is under development.

During the same time, the COMPARER project focused on the characterization of hot fuel associated to the unsteady behavior of a cooling loop. Some promising measurement are under further analysis and a small but complete specific test bench is currently under development for the testing of those methods. 


\section{Acknowledgments}

The authors wish to thank particularly F. Battin-Leclerc and R. Fournet of the DCPR laboratory and X. Rocourt and S. Bernard of the LEES laboratory.

The COMPARER project is funded by the Conseil Général du Cher (18), the Conseil Régional du Centre, the European Union (FRED, FEDER, FSE) and MBDA-France.

\section{References}

\footnotetext{
${ }^{1}$ F. Falempin, D. Scherrer, G. Laruelle, Ph. Rostand, G. Fratacci, J.L.Schultz, "French hypersonic propulsion program PREPHA -results, lessons \& perspectives", AIAA - 98 - 1565 - Norfolk, November 1998.

${ }^{2}$ Bouchez, M., and Beyer, S., "PTAH-SOCAR fuel cooled composite material structure for dual mode ramjet and liquid rocket engine - 2005 status", AIAA-2005-3434.

${ }^{3}$ Giraudot, T., Massot, A., Boselli, L., and Talbot, B., "Dual-fueled advanced high-speed ramjets : students paper", AIAA-2002-5214, Orléans, France, October 2002.

${ }^{4}$ Serre, L., Falempin, F., "PROMETHEE : The French military hypersonic propulsion Program", AIAA-2002-5141.

${ }^{5}$ Daniau, E., and Sicard, M., " Experimental and numerical investigations of an endothermic fuel cooling capacity for scramjet application ", AIAA-2005-.

${ }^{6}$ Daniau, E., Bouchez, M., and Gascoin, N., "Scramjet Active Cooling Analysis Using n-Dodecane as a Generic Endothermic Fuel", Thermochemical Processes in Plasma Aerodynamics, 12-14 July 2004, St Petersburg, Russia.

${ }^{7}$ Dahm, K.D., Virk, P.S., Bounaceur, R., Battin-Leclerc, F., Marquaire, P.M., Fournet, R., Daniau, E., and Bouchez, M., "Experimental and modeling investigation of the thermal decomposition of n-dodecane", Journal of Analytical and Applied Pyrolysis, 71 (2004) pp865-881.

${ }^{8}$ Gascoin, N. Gillard, P., Touré Y., Bernard, S., Daniau, E., Bouchez, M., 21 Octobre 2004, "Mesures et contrôle de paramètres pertinents pour la régulation d'un statoréacteur mixte refroidi", Troisième Rencontre Capteurs (Bourges).

${ }_{9}^{9}$ Ser, F., Heinrich, B., Luc-Bouhali, A., "Carburants liquides endothermiques : problématique du refroidissement et projet d'études expérimentales à l'ONERA", AAAF - Arcachon, France - March 2001.

${ }^{10}$ Dufour, E., Bouchez, M., "Semi-empirical and CFD analysis of actively cooled dual-mode ramjets", AIAA-20025126, Orléans, France.

${ }^{11}$ Buriko, Y., Vinogradov, V., Goltsev, V., Waltrup, P.J., "Influence of Active Radical Concentration on SelfIgnition Delay of a Propane/Air Mixture", AIAA 2001-3958 (2001).

${ }^{12}$ Kee, R.J., Grcar, J.F., Smooke, M.D. and Miller, J.A., "A Fortran Program for Modeling Steady Laminar OneDimensional Premixed Flames", Technical Report SAND85-8240, Sandia National Laboratories, 1985.

${ }^{13}$ Kee, R.J., Rupley, F.M. and Miller, J.A., "CHEMKIN-II: A Fortran Chemical Kinetics Package for the Anlysis of Gas-Phase Chemical Kinetics", Technical Report SAND89-8009, Sandia National Laboratories, 1989.

${ }^{14}$ Davidenko, D., Gökalp, I., Dufour, E., (2002) "Kinetic mechanism validation and numerical simulation of hypersonic combustion of methane-hydrogen fuel", AIAA 2002-5207.

15 Rothman L. S. et al., "The Hitran Molecular Spectroscopic Database And Hawks (Hitran Atmospheric Workstation): 1996 Edition", J. Quant. Spectrosc. Radiat. Transfer, Vol. 60, No. 5, (1998) 665-710.
} 